\title{
The Library Living Lab: A Collaborative Innovation Model for Public Libraries
}

\section{Fernando Vilariño, Dimosthenis Karatzas, and Alberto Valcarce}

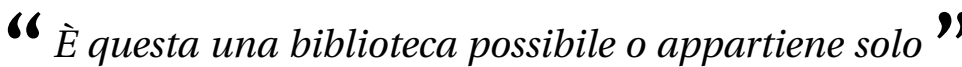 \\ a un universo di fantasia? \\ Umberto Eco (1932-2016) \\ In De Bibliotheca (1981) \\ About an imaginary - almost infinite - library
}

\begin{abstract}
New models of governance advance towards participatory schemes in which citizens not only play an active role in decision-making processes but also the processes by which new products and services are defined and introduced. In parallel, technological innovations, and the new horizons of creativity that they allow, open a huge range of options to innovation in all areas of society, particularly in the cultural field. Under these two premises - participation and innovation - the Library Living Lab initiative was born at the Public Library of Miquel Batllori Volpelleres in Sant Cugat del Vallès, Barcelona. The Library Living Lab is a space that gathers all stakeholders around the public library with the aim of exploring new methods and tools that allow us to enjoy culture both individually and collectively. This article describes how technology can be an enabling factor in a citizen-initiated grassroots project. The project implements a complete model of inter-institutional collaboration with all relevant actors around the living lab working group. The specific challenges of developing an open, flexible, and inter-connected space are identified, and the interaction dynamics based on a challenge-action-return methodology definition are described through practical examples. Our conclusions tackle the challenges of a horizon for the implementation of innovation initiatives - such as living labs - in public spaces.
\end{abstract}

\section{Introduction}

The Library Living Lab is essentially a space of experiences. It is a place where we can explore how technology transforms the ways in which we enjoy culture. This exploration is made possible by adopting the perspective of innovation through which the public library provides the context of a meeting place for diverse perspectives.

Living labs are defined by the European Union as usercentric innovation environments (Eskelinen et al., 2015), in which creators, managers, and users can participate in co-creating innovations that enable social and economic impact. For this impact to produce a significant change there must be an open and trustful ecosystem of various actors, from researchers (carriers of new ideas and technologies), administrators (policy makers and driving actors for the transformation of ideas into services), private organizations (allowing sustainable models), to ordinary people (for, with, and by whom innovation is taking place).

From this perspective, the Library Living Lab in Barcelona transforms a library space into a place in which all stakeholders, and specifically users of the public library, are invited to participate in the definition cycle of a potential service around an innovative experience. The result is a laboratory where it is possible to design prototypes of new tools and services, but it is also a social innovation laboratory where research is carried on the dynamics that lead to such innovation processes (Carayannis \& Campbell, 2009). In the specific case of the Library Living Lab, these activities are sustained on two fundamental pillars:

1. The exploration of technology as an enabling factor for experiences and transformative value services. 


\title{
The Library Living Lab: A Collaborative Innovation Model for Public Libraries
}

\author{
Fernando Vilariño, Dimosthenis Karatzas, and Alberto Valcarce
}

2. The continued questioning of the role of public space in society, transforming it into a place of innovation where we all are actors.

These ideas are developed in this article according to the following structure. First, we explain the origin of the project in the context of a more participatory society, and we describe our proposal for a new model of inter-institutional collaboration with all relevant stakeholders. Next, we describe the design and implementation of our innovation space, and the introduction of the "social challenge-action-return" strategy. Examples illustrate our approach and introduce the transformative value of the living lab in the library. Finally, we summarize the main findings and provide conclusions.

\section{Towards a More Participatory Society: A Project Born from a Citizen Initiative}

The Library Living Lab project is a successful example of a grassroots initiative that has taken the combined efforts of all participants (DG Connect, 2015). It was born out of necessity in response to an appeal by local residents of the municipality Volpelleres Sant Cugat del Vallès, Barcelona. Due to strong demand for homes in Sant Cugat in the late 1990s, the Council agreed to the development of the northern municipality. From 2000 to 2006 the first 3,352 planned dwellings were developed. Unfortunately, the bursting of the housing bubble in 2007 and 2008 halted the consolidation of the newly born district, which was populated mainly by young couples who had seen San Cugat as the ideal place to raise their families.

The economic crisis left half a district under development, and much of the projected infrastructure had not yet been built. In this context, some neighbours who worried about their present and future decided to organize themselves and founded the Association of Residents of the Neighbourhood of Volpelleres (AVBV, in their Catalan acronym). The AVBV represented a district with a population full of vitality and deeply rooted in information technology and communications. It was a well-connected area on the edge of a major concentration of universities and research centres, as well as a variety of major companies. However, many promised services were lacking. Notably, Sant Cugat's main plan included a proposal for the construction of a public library, although a timeline had yet to be determined. This lack of progress was seen by the AVBV as an opportunity, and its members began to work on a proposal for orienting the profile of this potential future library towards a technological focus.
This initiative - though still without form - arrived at the Computer Vision Centre (CVC), a joint partnership of the Government of Catalonia and the Universitat Autònoma de Barcelona (UAB). The CVC is a research centre leader in the area of artificial intelligence for image and video analysis, with a strong commitment to local and international projects in different fields of application. At that time, the CVC was implementing a strategic bet oriented towards the application of its core technologies in the field of culture, while investigating novel paradigms for the rapid transfer of research outcomes to the public. When the citizens representing the AVBV explained to the CVC that they wanted something innovative for the new public library, the centre proposed the creation of the first "Library Living Lab" (described below). The proposal was crafted in 2011 and it was jointly submitted by the AVBV to the mayor of Sant Cugat, who received it positively and gave it its institutional support.

The result was that the Volpelleres Library project was prioritized by the municipality. The university took on this project as part of its strategic plan, and the project definition phase began with the formation of a working group that included representatives from the municipality, the provincial government, the CVC, the university, and the AVBV. In 2014, the agreements for the implementation phase of the project were signed, and the library opened its doors in May 2015. In the summer of that same year, the Library Living Lab was accepted in the European Network of Living Labs (ENoLL; enoll.org), Then, in October of the same year, the citizens themselves presented the activities to the library users during a grand opening party. This initial implementation was run as a pilot until 2018, when it reached the two key milestones of the consolidation phase: the final model of governance was defined and the sustainability model was agreed.

\section{A New Model of Inter-Institutional Collaboration with all Relevant Stakeholders}

The launch of the Library Living Lab involved the definition of the lab's own dynamics around a permanent working group, in which several mechanisms of interinstitutional collaboration have been deployed. The permanent working group brought together representatives of the five participating institutions, who each have different roles, plans of action, and objectives (Table 1). The aim of the working group was the alignment of all these various objectives for the definition of the master lines of work. The group gathered for bimonthly meetings, and its first task, and perhaps its 


\section{The Library Living Lab: A Collaborative Innovation Model for Public Libraries}

Fernando Vilariño, Dimosthenis Karatzas, and Alberto Valcarce

Table 1. Participating institutions in the Library Living Lab's permanent working group

\begin{tabular}{llll} 
Institution & Representation & Role & Objectives \\
\hline City of Sant Cugat del Vallès & $\begin{array}{l}\text { Library Service Manager } \\
\text { Provincial Council of } \\
\text { Barcelona (DiBa) }\end{array}$ & $\begin{array}{l}\text { Responsible for } \\
\text { municipal allocations } \\
\text { of Libraries }\end{array}$ & $\begin{array}{l}\text { Provide high-quality services in the area } \\
\text { of culture }\end{array}$ \\
\hline $\begin{array}{l}\text { Universitat Autònoma de } \\
\text { Barcelona (UAB) }\end{array}$ & $\begin{array}{l}\text { Head of the Office for } \\
\text { Strategic Projects }\end{array}$ & $\begin{array}{l}\text { Researchers } \\
\text { 2016) }\end{array}$ & $\begin{array}{l}\text { Develop the role of the public spaces in } \\
\text { the network of }>250 \text { libraries as meeting } \\
\text { points and repositories of knowledge }\end{array}$ \\
\hline $\begin{array}{l}\text { Computer Vision Centre } \\
\text { (CVC) }\end{array}$ & $\begin{array}{l}\text { Associate Director and } \\
\text { Research Staff }\end{array}$ & $\begin{array}{l}\text { Extension of the university influence to } \\
\text { the territory }\end{array}$ \\
\hline $\begin{array}{l}\text { Association of Neighbours } \\
\text { of Volpelleres (AVBV) }\end{array}$ & $\begin{array}{l}\text { Citizens; members of the } \\
\text { association }\end{array}$ & $\begin{array}{l}\text { Instigator of the } \\
\text { initiative and final } \\
\text { recipients of its services }\end{array}$ & $\begin{array}{l}\text { Research, technology transfer and } \\
\text { training in computer vision with and by } \\
\text { the final users (citizens) }\end{array}$ \\
\hline
\end{tabular}

most important one, was the definition of a common language to share across all institutions. This task was accomplished by "learning to talk" to other members. This learning comprised, among other things: fixing terminology and procedures, defining new fields of common knowledge, understanding what was and what was not allowed in the public space, understanding the priorities and dynamics of each institution, and establishing timeframe expectations, which were also different for each institution.

A key feature of such a group is that all the actors are directly involved in decision making, and this involvement is always based on needs and opportunities. This situation represents a new paradigm of inter-institutional collaboration. On the one hand, it allows for the definition of actions and services with high added value given that they are originally based on the real needs of the different participants. On the other hand, it requires public institutions to take on higher exposure (accountability) and public visibility of their performance and responsiveness. The main outcome of this process is the agreed prioritization of work lines, which form the basis for the subsequent concrete definition of innovation activities.

\section{The benefits to each institution and the results of the} collaboration

Joint collaboration for the definition of common lines of work must allow an objectively verifiable benefit to all participants in order to ensure a sustainable project.
In the case of the Library Living Lab, the benefits to each institution can be summarized as follows:

1. The City of Sant Cugat del Vallès benefits through the creation of space for experiences by its residents. It has added value and provides a meeting place for cultural projects with all social segments of the city. This space enables the design of new models of governance focused on citizen participation.

2. The Provincial Council of Barcelona benefits through the creation of an innovation space - a place in which to securely study and define prototypes, methodologies, and protocols that may become part of new services. This endows the Library Network of Barcelona Provincial Council with a place to identify the challenges that arise on a day-by-day basis, to explore fitted solutions, to test proposals and to propose answers, all by-with-and-for the users. The scalability is guaranteed by translating the valuable solutions obtained in the Living Lab to the rest of the libraries of the Network.

3. The Universitat Autònoma de Barcelona benefits from the implementation of its living lab, which aligns with its policy of extended outreach into its surrounding territory, and it provides its scientific community with a space for citizen science.

4. The Computer Vision Centre benefits from the creation of an experimentation space for technologies 


\title{
The Library Living Lab: A Collaborative Innovation Model for Public Libraries
}

\author{
Fernando Vilariño, Dimosthenis Karatzas, and Alberto Valcarce
}

with high added value and an implementation space for rapid technology transfer to society though fast prototyping.

5. The Association of Neighbours of Volpelleres achieves strong revitalization of its neighbourhood, access to a collection of innovative activities, and a place to enjoy culture through the latest technological tools.

Finally, the benefits of this collaboration are expected to extend beyond the membership of the working group. The citizens of Barcelona are the ultimate recipients of the benefits of the Library Living Lab, but the scheme also enables participation at the level of specific projects to other actors such as companies, which can play a key role as economic impact drivers by benefiting the entire social fabric with the emergence of new cultural products and services. In this way, the quadruple-helix model is completed.

\section{Design and Implementation of an Innovation Space: Open, Flexible and Interconnected}

One of the most important questions about an innovation space is the design of the space itself, because a poor design jeopardizes the functionality of the project. In the case of the Library Living Lab, the specific area consists of $110 \mathrm{~m}^{2}$ within the Public Library of Volpelleres. However, although limited and confined to this area, the presence of the living lab transforms the whole library, inspiring its own culture of innovation that extends to every corner of the building and is shared by all of its working staff.

During the definition phase of the project, the members of the working group had the opportunity to engage directly with the team of architects in the design of the Library Living Lab in order to implement a space with three fundamental characteristics: it had to be open, flexible, and interconnected.

1. An open space: From a perspective of accessibility, the space is separated both physically and acoustically by a glass wall that makes it possible to visualize the activities that are taking place within it at all times. It is an open space without barriers, which invites curious people to enter, since here "openness" also means visually accessible. Access is provided through a small door at the back of the space; this entrance is designed to not disturb the ongoing activities, but it is also possible to open a large gateway through a sliding door that opens the space physically by merging it with the whole volume of the library.
2. A flexible space: All items of furniture, chairs, etc. are light and mobile, and they can be quickly adapted for any activity. This flexibility was a basic premise of the design and reduces the likelihood that innovation processes may be constrained by the physical limitations of the space.

3. An interconnected space: There is a high density of power and Ethernet connections on the floor and walls, a separate WiFi network that does not interfere with the Internet network of the wider library, and accessibility and high-capacity plugs on the ceiling, with anchoring mechanisms that allow the installation of screens, cameras, projectors, and other electronic devices.

The spirit of the design of this space is, in short, to create an infrastructure that makes it possible to live new experiences in a comfortable way, that enables rapid changes from activity to activity, and that allows the possibility of using diverse electronic devices connected to the network without limitations.

\section{The Dynamics of Innovation: Joint Definition of Social Challenge-Action-Return}

Innovation processes share common dynamics that are tailored to specific contexts. These dynamics crystallize in the Library Living Lab in three distinct stages: identification of a social challenge, design and implementation of a specific action, and definition of a return. This approach is aligned with the main pillars described in the Responsible Research and Innovation approach (European Commission. 2016), which is used to tackle dimensions such as awareness, transparency, and openness.

1. Social challenge: In order to achieve social impact, it is essential for the activities of the Library Living Lab to be designed in order to advance the resolution of some of the challenges currently faced by our society. These challenges are identified within the working group, which prioritizes them according to the values and convergent interests of the various actors. This process ensures real benefits to all participants in the terms described above.

2. Action: Having identified a challenge, it is necessary to define a concrete action for the process of innovation, the typology of which must be specifically adapted and suited to the chosen challenge. There is no general action scheme, but the opportunity to select the most appropriate solution ensures efficient approaches to the proposed challenges. 


\section{The Library Living Lab: A Collaborative Innovation Model for Public Libraries}

Fernando Vilariño, Dimosthenis Karatzas, and Alberto Valcarce

3. Return: Finally, it is essential to define a specific and objectively verifiable return, which is obtained as a result of the innovation action. This return is the commitment that the actors have towards the participants and the way in which the benefit of participation is identified for all of the Library Living Lab experiences.

Thus, the triplet of Challenge-Action-Return must be present for each activity in the laboratory and should be communicated efficiently to all actors, thereby ensuring informed and responsible decision making based on common knowledge (DiBa, 2016). Table 2 lists a number of challenges, actions, and potential returns from the early experiences with the Library Living Lab. Throughout the next section, a more detailed description of the implementation of the methodology is illustrated in three practical examples.

\section{Examples of Experiences born in the Library Living Lab}

The methodology introduced in the preceding paragraphs results in a list of activities that implement the triplet of challenge-action-return. We must emphasize that this list of activities is always dynamic: once an activity has been completed in the laboratory (prototyping), all the comments, conclusions, and lessons learned by the various actors are collected, and the final result can be (though is not necessarily) the viability of a new service, a new tool, etc. It is at this point that the identification of a new challenge will initiate a brandnew cycle of innovation, thus keeping active the essence of the creative process and the spirit of the innovation space. The further implementation of an actual product, policy, or service from the studied prototype relies then on the specific drivers of the socio-economic impact. The Library Living Lab contributes with its added value to the definition processes.

During the first six months of its operation, the Library Living Lab implemented a set of activities following this vision. Notable examples of these activities include the following:

1. The Library Visits the Museum: seeks to break down the walls that separate museums and libraries.

2. Interest Group on Educational Apps: investigates methods and tools for learning by using mobile applications in schools.

3. Interest Group on 3D Printing: collaboratively works to define the role of libraries in creation activities through $3 \mathrm{D}$ printers.

4. I Am My Own Drawing: aims to re-define the current service, which is titled "Story Time".

Table 2. Examples of challenges, actions, and returns identified at the Library Living Lab

\begin{tabular}{|c|c|c|}
\hline Social Challenges & Actions & Returns \\
\hline $\begin{array}{l}\text { - The library as a meeting point } \\
\text { - Link between physical and digital } \\
\text { documents } \\
\text { - Interaction between galleries, libraries, } \\
\text { archives, and museums (GLAM) } \\
\text { - (Re-)valorization of digital collections } \\
\text { - Definition of the role of mobile } \\
\text { technologies } \\
\text { - Novel paradigms of education in open } \\
\text { environments } \\
\text { - Opportunities related to 3D printing } \\
\text { - Collaborative creation: novel paradigms of } \\
\text { storytelling }\end{array}$ & $\begin{array}{l}\text { - Design, implementation, and } \\
\text { validation of a software tool } \\
\text { - Definition and implementation of the } \\
\text { dynamics of a fortnightly activity } \\
\text { - Set up of a citizen science experiment } \\
\text { - Assessment of a novel methodology } \\
\text { - Creation of an autonomous working } \\
\text { group around a collective project } \\
\text { - Definition of a prototype validation } \\
\text { experience }\end{array}$ & $\begin{array}{l}\text { - An open source software } \\
\text { application } \\
\text { - A new permanent activity } \\
\text { - A new service for the Library } \\
\text { Network } \\
\text { - An enriching cultural experience } \\
\text { - An object (physical or digital) of } \\
\text { collective creation } \\
\text { - A novel methodology or protocol }\end{array}$ \\
\hline
\end{tabular}




\section{The Library Living Lab: A Collaborative Innovation Model for Public Libraries}

Fernando Vilariño, Dimosthenis Karatzas, and Alberto Valcarce

5. Scientific experiments: aim to advance novel models of participative citizen science.

6. Workshops for Social Innovation: seeks to root the dynamics of creativity and participation at a local level.

7. Historical Images of the Neighbourhood: makes digital collections of public archives and collections available to citizens using new tools to access and view multimedia content.

8. Nature in HD: explores how to give value to photographic exhibitions with contributions from users by linking physical photographs with digital content.

The next section expands on three of these illustrative examples of prototypes (both products and services) cocreated at the Library Living Lab: The Library Visits the Museum, I Am my Own Drawing, and the Interest Group on Educational Apps. For a full list of the prototypes and activities, please visit librarylivinglab.com.

\section{The Library Visits the Museum}

Challenge: Breaking down the walls between museums and libraries and (re-)valorizing digital collections.

Action: Design and implementation of tools, protocols, and activities for access to digital collections of museums.

Return: A prototype service: "The Library Visits the Museum".

This fortnightly activity gathers users interested in learning about the contents of large and small museums that have diverse digitized their collections and made them accessible online. It begins with a selection of the museum that is going to be visited. The library staff responsible for the activity prepare a file with the historical and artistic context of these museums. Each museum is then analyzed in terms of technical possibilities and the best form of interaction is determined based on the capabilities of each museum: pictorial analysis is possible when HD items can be visualized in large-screen format (Figure 1); analysis focused on the physical spaces is an option when a realistic representation of the rooms exhibiting the collections is accessible; the study of the architecture of the building hosting the museum becomes a relevant option when it is possible to navigate into a virtual space, etc. In particular, the analysis considers the potential for direct inter- action through the presence of human avatars (Bertrand et al., 2014) to perform a visit, which is relayed over the Internet to the library users, who can guide the visit from the Library Living Lab physical space. The result of this experience is a prototype service that is dynamically updated each session based on the lived experiences, by adding new tools and by identifying the dynamics and the minimum requirements necessary to implement such a service.

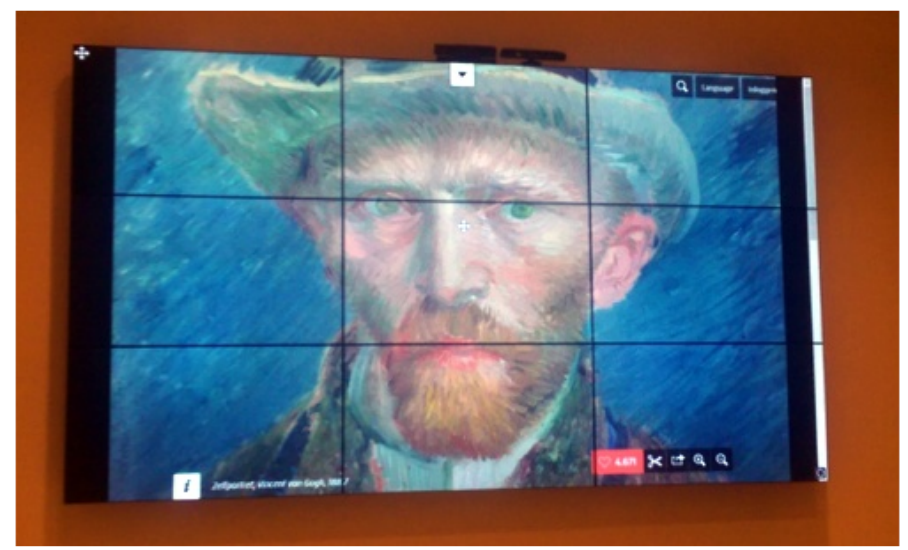

Figure 1. The Library Visits the Museum: An initiative of the Library Living Lab

\section{Am My Own Drawing}

Challenge: New paradigms of storytelling.

Action: Programming of new software and definition of the dynamics of a workshop for collective creation.

Return: An open source software application with Creative Commons license. A workshop for the children of the community. A digital story created in a collaborative way.

The current library service, "Story Time", is a series of scheduled 1-hour sessions during which a storyteller who relates a tale to a group of children, sometimes using some theatrical interaction. Next, the children collectively create their own script of a story, for which they then draw their own characters and scenarios, which will be digitized under the supervision of a library activity instructor. The children then stage their own collaborative story performance, which is displayed on a large screen with digitized scenarios and characters. By using gesture detection technology, the movements of the children are translated to the characters shown on screen in order to animate them, thereby 


\section{The Library Living Lab: A Collaborative Innovation Model for Public Libraries}

Fernando Vilariño, Dimosthenis Karatzas, and Alberto Valcarce

transferring the children's gestures to the digitized characters (Figure 2). The story is recorded and it becomes part of the catalogue of collaborative stories. This experience is innovation to a previously existing non-digital service.

\section{Working Group on Educational Apps}

Challenge: Defining the role of mobile technologies in educational settings, both regulated and unregulated.

Action: Assess the most relevant apps and collect a set of good practices.

Return: Novel learning paradigms for schools and unregulated educational environments using mobile technologies.

A group of users consisting of a number of teachers from different schools in Sant Cugat and other library users interested in mobile technologies gather fortnightly to present a selection of mobile apps used in their teaching experiences (Figure 3). The goal is to gather not only the technical issues but also the methodological aspects associated with the mobile learning activities. One of the outcomes consists of the definition of the indicators of an evaluation grid suitable for educational environments, and the assessment of each app regarding the defined grid. The result is a new shelf in the library, in this case a software shelf, focused on educational tools with valuable feedback provided by critical stakeholders. In this way, the library becomes a repository of apps that provides added value that is not available in existing repositories and app stores.

\section{The Transformative Value of the Living Lab in the Library}

The existence of the living lab enriches the daily life of the library. The continued presence of people with various profiles - scientists, artists, entrepreneurs, etc., all of whom are also "new" library users - provides novel entry points for knowledge and potential opportunities for multidisciplinary interchange among all participants, starting with the library users and finishing with the professionals who provide the services. There is also a direct impact in terms of inclusion: the new range of experiences broadens the scope of the library users, even by attracting people who otherwise would not visit the library, and by increasing the possibility of user participation in joint projects with rich profiles.

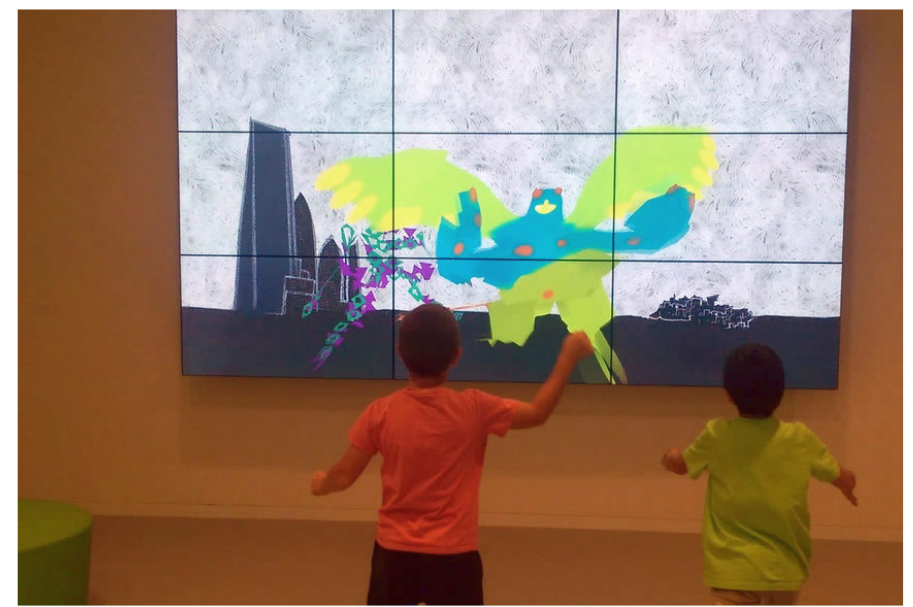

Figure 2. I Am My Own Drawing: An initiative of the Library Living Lab

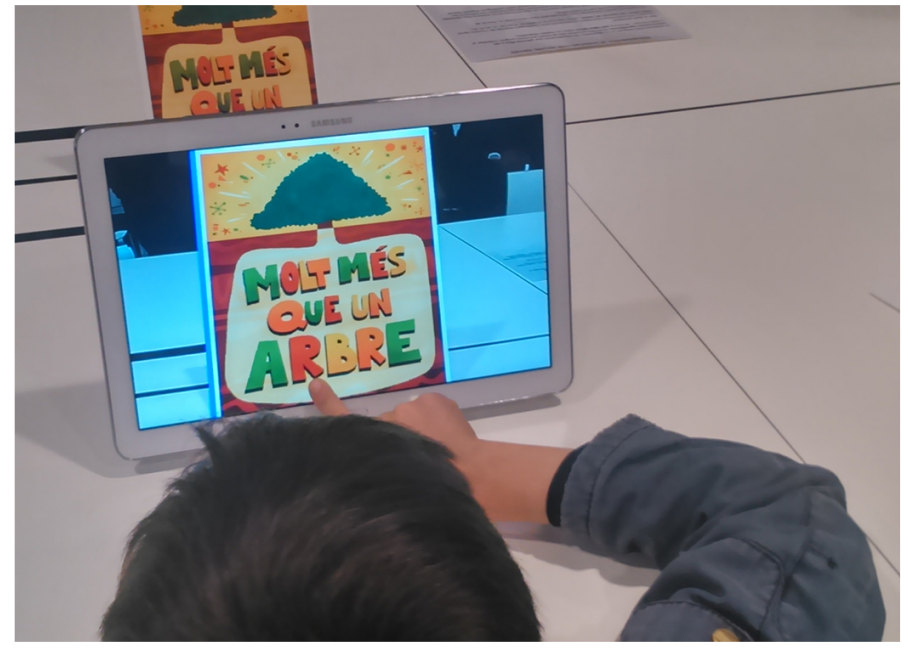

Figure 3. Working Group on Educational Apps: An initiative of the Library Living Lab

At the institutional level, the presence of this genuine innovation ecosystem effectively implements the role of public space as a meeting place for all stakeholders. This ecosystem also draws small and large companies into the public and cultural sphere and promotes their participation in public initiatives. The local library expands its area of action, and this allows multiple projects of not only local but also regional and international reach. The library is thus transformed into a place where every day, something that was not planned can happen, not as a result of improvisation but of a collaborative work ensemble, with models more open and flexible programming. 


\section{The Library Living Lab: A Collaborative Innovation Model for Public Libraries}

Fernando Vilariño, Dimosthenis Karatzas, and Alberto Valcarce

\section{Conclusion}

Our experiences with the Library Living Lab, as presented in this article, allow us to identify some of the most relevant near-future challenges arising in the context of this innovation initiative. These challenges serve as a starting point for the reflexion on the "library of the future" and they were selected to be part of the white book for the main directives on Future Public Libraries by the Barcelona Provincial Council (Vilariño et al., 2016):

1. The Library of Living Lab was born from a citizen initiative. It will be important to implement social monitoring tools to identify these kinds of initiatives, and also to accompany them with dynamic instruments for the implementation of viable innovative approaches. The current processes of public administrations are not adapted to the flexibility needed, and it is necessary to develop methodologies of interdisciplinary work in inter-institutional teams, particularly when hosting citizen participation. This will imply a higher exposure and visualization of the performance and responsiveness of public institutions, which should be channelled in an efficient way.

2. In the medium term, the design of public spaces should be transformed into a community project: social actors must be able to participate in the design process in order to make it their own. Participation in the process of defining spaces not only ensures technical optimization based on good design, but also fundamentally integrates a project space within the community.

3. New paradigms of collaboration among all actors of society necessarily imply the need for specific models of sustainability. Novel instruments for co-financing from private patronage and sponsorship within the public space must be investigated to enable quick response at the budgetary action level for innovation projects.
4. Citizen participation in the processes of innovation opens up many questions related to management of intellectual property rights and exploitation of emerging innovations. These issues can only be solved, given their high degree of complexity and peculiarities, on a day-to-day basis. We must therefore identify monitoring and protection mechanisms of the innovation outcomes, which must become play a paramount role in the innovation processes.

In short, the fundamental challenge of innovation spaces such as the Library Living Lab is to facilitate, in an efficient way, the direct contribution of responsible citizens in the processes of defining and implementing new sustainable services and activities (European Commission, 2016). This will provide a value that can only be achieved from the participation of all stakeholders, and through the definition of process for effective policy making. Technology will play a very strong role as an enabling factor, but it is around people - and mainly with regards the mechanisms of individual and inter-institutional collaboration - that we are facing the most significant challenges. Only by truly engaging with the people - the users and stakeholders set to benefit from the innovation activities - can society obtain a transformative socio-economical impact from the innovations arising from these collaborative processes, such as those brought to life through the Library Living Lab.

\section{Acknowledgements}

This article was developed from a paper presented at the ISPIM Innovation Conference in Stockholm, Sweden, June 17-20, 2018. ISPIM (ispim-innovation.com) - the International Society for Professional Innovation Management - is a network of researchers, industrialists, consultants, and public bodies who share an interest in innovation management. The authors wish to acknowledge the editor and reviewers of the TIM Review for their substantial contributions in improving the quality of the article. 


\section{The Library Living Lab: A Collaborative Innovation Model for Public Libraries}

\section{Fernando Vilariño, Dimosthenis Karatzas, and Alberto Valcarce}

\section{About the Authors}

Fernando Vilariño is Associate Director of the Computer Vision Centre and Associate Professor at the Universtitat Autònoma de Barcelona. He holds a $\mathrm{PhD}$ in Computer Vision and is a Lecturer in Machine Learning and Robotics. He is Co-Founder of the Library Living Lab in Barcelona, and he is President of the European Network of Living Labs. In 2014, he received a Google Research Award in the line of Eye-Tracking Interaction.

Dimosthenis Karatzas is Associate Director of the Computer Vision Centre and Associate Professor at the Universitat Autònoma de Barcelona. He holds a $\mathrm{PhD}$ in Computer Vision and is a Lecturer in Artificial Intelligence. He is Co-Founder of the Library Living Lab in Barcelona. In 2013, Dimosthenis received the prestigious IAPR/ICDAR Young Investigator Award and, in 2016, he received the Google Research Award in the line of Machine Perception.

Alberto Valcarce is President of the Association of Neighbours Volpelleres in Sant Cugat del Vallès, Barcelona. He is a lawyer and holds an MSc degree in Water Management. He participated in the inception, design, and implementation of the Library Living Lab in Barcelona.

\section{References}

Bertrand, P., Gonzalez-Franco, D., Cherene, C., \& Pointeau, A. 2014. The Machine to Be Another: Embodiment Performance to Promote Empathy among Individuals. Be Another Lab.

Carayannis, E. G., \& Campbell, D. F. 2009. 'Mode 3' and 'Quadruple Helix': Toward a 21st Century Fractal Innovation Ecosystem. International Journal of Technology Management, 46(3-4): 201-234. http://dx.doi.org/10.1504/IJTM.2009.023374

DG Connect, 2015. Open Innovation 2.0 Yearbook. Brussels: European Commission. http://doi.org/10.2759/92658

DiBa. 2016. Pla d'actuació 2016. Gerència del Servei de Biblioteques. Diputació de Barcelona (DiBa).

Eskelinen, J., Robles, A.G., Lindy, I., Marsh, J., \& Muente-Kunigami, A. 2015. Citizen-Driven Innovation: A Guidebook for City Mayors and Public Administrators. World Bank, Washington, DC, and European Network of Living Labs. http://hdl.handle.net/10986/21984

European Commission. 2016. Responsible Research and Innovation Europe's Ability to Respond to Societal Challenges. Brussels: European Commission. http://doi.org/10.2777/11739

Vilariño, F., Karatzas, D., Catalan, M. A., \& Valcarce, A. 2016. Un horitzó per la Biblioteca Pública com a lloc d'innovació $i$ creativitat. El Library Living Lab de Volpelleres. Barcelona: Llibre Blanc de la Xarxa de Biblioteques de la Diputació de Barcelona.

Citation: Vilariño, F., Karatzas, D., \& Valcarce, A. 2018. The Library Living Lab: A Collaborative Innovation Model for Public Libraries. Technology Innovation Management Review, 8(12): 17-25.

http://doi.org/10.22215/timreview/1202

Keywords: living lab, library, participatory, innovation, cultural spaces, public spaces, technology 


\section{Academic Affiliations and Funding Acknowledgements}

Canadà
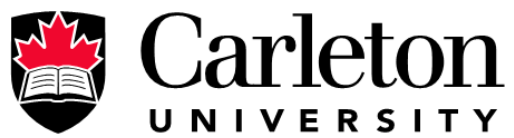

U N I V E R S I T Y

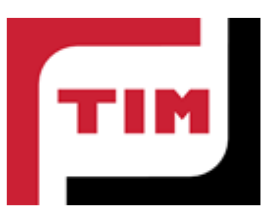

The Federal Economic Development Agency for Southern Ontario (FedDev Ontario; feddevontario.gc.ca) is part of the Innovation, Science and Economic Development portfolio and one of six regional development agencies, each of which helps to address key economic challenges by providing regionallytailored programs, services, knowledge and expertise.

- The TIM Review receives partial funding from FedDev Ontario's Investing in Regional Diversification initiative.

Technology Innovation Management (TIM; timprogram.ca) is an international master's level program at Carleton University in Ottawa, Canada. It leads to a Master of Applied Science (M.A.Sc.) degree, a Master of Engineering (M.Eng.) degree, or a Master of Entrepreneurship (M.Ent.) degree. The objective of this program is to train aspiring entrepreneurs on creating wealth at the early stages of company or opportunity lifecycles.

- The TIM Review is published in association with and receives partial funding from the TIM program. 